\title{
MOVIMENTOS SOCIAIS COMO TEÓRICOS POLÍTICOS: WOLIN, IDEIAS E POLÍTICAS PÚBLICAS*
}

\author{
Renato Perissinotto \\ é pesquisador CNPQ e professor associado do Programa de Pós-Graduação em \\ Ciência Política (UFPR).Curitiba, PR. Brasil.E-mail:<monseff@gmail.com> \\ José Szwako \\ é professor adjunto do Instituto de Estudos Sociais e Políticos (IESP-UERJ). \\ Rio de Janeiro, RJ. Brasil.E-mail: <zeszwako@iesp.uerj.br> \\ http://dx.doi.org/10.1590/0102-231263/102
}

Na sua introdução a A alma e as formas, Judith Butler, ao comentar o conceito de forma de Georg Lukács, observa que "a forma está sempre em conexão com a vida, com a alma, com a experiência; a vida produz a forma, mas a forma destila a vida" (Butler, 2015, p. 16). Essa metáfora captura admiravelmente bem a natureza complexa das relações entre determinações objetivas que constrangem os atores no mundo social e formulações ideacionais que elaboram para dar conta desse mundo. Contra uma visão estritamente formalista que confere às ideias realidade própria, afirma-se que estas só adquirem sentido e força social quando conectadas ao contexto histórico; contra um reducionismo simplório, defende-se que o processo de pensar a realidade concreta, o trabalho de categorizá-la, de procurar entendê-la e justificá-la, é, por si só, constitutivo dessa realidade. Mais do que isso, como dizem Berger e Luckmann, toda realidade é interpretada e grande parte da luta política é

\footnotetext{
"Agradecemos aos pareceristas anônimos de Lua Nova e a San Romanelli Assumpção pelas valiosas sugestões.
} 
travada precisamente em torno dessa interpretação (Berger e Luckmann, 1994, p. 35).

Este artigo inscreve-se nesse espírito. Pretendemos discutir a importância das ideias tanto para definição das situações políticas quanto para produção de diagnósticos sobre a realidade. No que se refere à definição das situações políticas, este texto é tributário de uma literatura recente no campo da ciência política conhecida como "virada ideacional" (Béland, 2005; 2009; 2010; Béland e Hacker, 2004; Berman, 1998; 2001; 2013; Blyth, 1997; 2001; 2002; 2003; Goldstein, 1988; Goldstein e Keohane, 1993; Hay, 1996; 2008; 2011; Schmidt, 2010; 2014; Schmidt e Radaelli, 2004; Schmidt e Thatcher, 2013). No que diz respeito à produção de diagnósticos da realidade, este texto ampara-se em longa tradição das ciências sociais e da teoria política. Ao juntarmos as duas perspectivas, pretendemos pensar os movimentos sociais não apenas como carriers de ideias (Berman, 1998) ou como political entrepreneurs (Kingdon, 2014), mas também como "teóricos políticos", no sentido atribuído a esse termo por Sheldon Wolin (1969).

Nosso objetivo central tem duas dimensões interligadas, a primeira consiste em utilizar a literatura que discute o impacto das ideias na definição das situações políticas para pensar a dimensão ideacional dos movimentos sociais e seus efeitos de "generificação"1 das políticas públicas e, baseando-se nessa discussão e lançando mão das contribuições da teoria política, mostrar que os movimentos sociais, ao fazerem isso, não apenas produzem impactos ideacionais sobre normativas estatais, como também conseguem elaborar análises complexas sobre a realidade que encerram e veiculam eixos distintivos de uma teoria política. O que pretendemos mostrar é que os movimentos sociais não têm apenas ideias,

1 Tomamos aqui "generificação" e gender mainstreaming como sinônimos; cf. Walby (2005). 
mas são formuladores de diagnósticos e prescrições sobre um mundo visto por eles como sistematically mistaken (Wolin, 1969, p. 1080).

Para a realização desses objetivos, este estudo tem uma parte em que analisamos como o tema do impacto das ideias foi mobilizado por três clássicos, Marx, Weber e Tocqueville, na dupla direção pretendida por nós neste artigo. Ainda nesse item, utilizamos Sheldon Wolin para apresentar nossa definição de teoria política. Em seguida, mostramos como problemas presentes nos clássicos ainda de forma embrionária foram tratados pela literatura contemporânea e que categorias forjou para pensá-los. Nesse item reconhecemos avanços metodológicos inegáveis dessa literatura, mas também apontamos retrocesso importante que se expressa em seu distanciamento em relação à potência crítica da teoria política. Já na terceira parte, utilizamos três momentos que ilustram empiricamente as dinâmicas e interações implicadas na relação entre ideias e políticas públicas. Esse caso se refere às organizações do feminismo paraguaio, às suas demandas e interações com atores e instituições daquele sistema político, analisadas alhures (Szwako, 2012). A título de conclusão, pretendemos discutir os limites da literatura centrada na relação entre ideias e política para pensar esse objeto e sugerimos que podem ser superados se deixarmos de pensar movimentos sociais como meros "portadores de ideias" para vê-los também como formuladores, não só de políticas públicas, mas de teorias políticas. Dito de outra forma, inspirados pela virada ideacional, visualizamos no modus operandi dos movimentos sociais uma maneira de fazer teoria política que tem longa tradição na história do pensamento e que, porquanto desempenham funções cognitivas, podem também ser pensados como "teóricos políticos coletivos". 


\section{0 lugar das ideias nos clássicos}

Onde reside a maior contribuição dos clássicos no que diz respeito ao problema do impacto das ideias sobre fenômenos políticos? Certamente não na afirmação trivial de que "ideias importam". De fato, seria estranho pensar que as ideias que habitam a cabeça dos agentes sociais não fizessem qualquer diferença para o entendimento de suas escolhas e decisões (Hall, 1993). ${ }^{2}$ A contribuição dos clássicos, porém, transcende o campo da mera plausibilidade e constitui-se numa primeira tentativa de analisar alguns fenômenos históricos relevantes lançando mão das ideias como fator importante para sua compreensão. No entanto, mais do que reconhecer que ideias produzem impactos, esses autores foram, eles próprios, produtores de ideias que tiveram grande efeito sobre a luta política. Eram, nesse sentido, analistas e teóricos políticos. Como conjugam essas duas atividades é o que pretendemos discutir, brevemente, neste item.

234 Convém primeiramente justificar a escolha desses três autores. Essa justificativa baseia-se em quatro argumentos, dois corriqueiros e outros dois menos triviais. $\mathrm{O}$ primeiro diz respeito ao esforço que fizeram para dar tratamento teórico razoavelmente sistemático ao problema do impacto das ideias sobre o desenvolvimento dos fenômenos políticos. O conceito de ideologia em Marx, a ênfase de Tocqueville nos costumes e as considerações de Max Weber sobre como as "visões de mundo" conduzem ações orientadas pelos interesses são contribuições decisivas nesse sentido. Em segundo lugar, encontram-se as contribuições substantivas e consagradas dos três autores nesse campo. As "análises históricas" de Marx, as observações de Tocqueville sobre o papel da filosofia na derrocada do antigo regime e as considerações de Weber sobre éticas religiosas e seu impacto sobre o

\footnotetext{
2 A plausibilidade da proposição, porém, não convence a todos. Ver, por exemplo, a defesa da intercambialidade dos atores na teoria da escolha racional. Cf. Tsebelis (1998).
} 
mundo material são patrimônios das ciências sociais. Há, no entanto, dois outros aspectos fundamentais, e, como dissemos, menos corriqueiros, para se lançar mão desses três autores.

O primeiro deles refere-se ao modo de análise presente em suas investigações quando se trata de pensar o peso das ideias na explicação dos fenômenos políticos. Apesar das grandes diferenças epistemológicas e políticas entre Marx, Weber e Tocqueville, há algo que os unifica quando se trata de pensar esse problema, a saber, todos estabelecem relação complexa entre os constrangimentos do mundo objetivo e o impacto das ideias sobre os processos desse mundo. Dito de outra forma, os três autores atribuem papel ativo ao modo como os atores sociais e políticos pensam o mundo e a si próprios, mas, ao mesmo tempo, afirmam que esse papel se desenrola em estreita relação com as condições objetivas nas quais agem esses mesmos atores. A leitura de O 18 Brumário de Luís Bonaparte (Marx, 2008a), A psicologia social das religiões mundiais (Weber, 1981) e $O$ antigo regime e a revolução (Tocqueville, 2013) mostram quão pueril é interpretar tais autores na chave disjuntiva entre materialismo e idealismo. Ao contrário, em todos presenciamos esforço em conectar a "realidade objetiva", herdada e impositiva, com a interpretação que os atores sociais fazem dela.

No caso de Marx a própria simbologia política herdada da antiguidade clássica é parte essencial dos constrangimentos que atuam sobre os atores políticos e limitam suas escolhas. Toda a análise contida em O 18 Brumário é grafada dentro do espírito de que, sem dúvida, as forças materiais e os conflitos de classe são constrangimentos incontornáveis, mas é por meio das "formas ideológicas que os homens adquirem consciência desse conflito e lutam para resolvê-lo" (Marx, 2008b, p. 302). Nesse sentido, a despeito dos constrangimentos materiais, o conjunto de ideias, percepções, preconceitos, filosofias, visões de mundo que habitam a 
cabeça dos agentes como um “duende" são componente essencial à teoria da ação política de Marx (Maguire, 1984).

Em Weber é especialmente sintomático desse espírito sua combinação entre "interesses materiais e ideias". Para o autor, situações de interesse, isto é, as posições que os atores sociais ocupam em estruturas de poder (econômicas, institucionais, religiosas, ou de qualquer outro tipo) interagem com ideias segundo as quais esses mesmos atores interpretam tais posições. As ideias, como "manobreiros", conduzem a ação impulsionada pela dinâmica dos interesses. É o jogo permanente entre interesses institucionalizados e ideias institucionalizadas que constitui a ação social; apenas interesses interpretados e ideias carregadas de interesses são sociologicamente relevantes (Roth e Schluchter, 1979, p. 17).

Por fim, Tocqueville talvez seja o autor que mais se aproxima da literatura contemporânea quando, no capítulo 1 236 da terceira parte de seu livro, descreve como a filosofia do século XVIII encontrou condições políticas específicas que potencializaram seu impacto. Seu potencial desestabilizador veio do fato de que a centralização política e administrativa promovida pela monarquia absolutista, ao expulsar os franceses da atividade política, deixou esse povo à mercê de uma "política abstrata e literária" que, frente às iniquidades e privilégios persistentes, aumentou ainda mais o poder de fogo. Na bela síntese de Chartier, "ao enfraquecer a "vida pública' removendo a nobreza e a burguesia do exercício do poder, a própria monarquia criou condições que autorizavam a hegemonia 'filosófica'” (Chartier, 1991, p. 37).

Como se nota, então, retomando o comentário de Butler a Lukács, não há nos clássicos redução das condutas à "vida", nem visão delirante do papel autônomo da "forma". Unifica-os, ao contrário, o pressuposto de que, mesmo em condições profundamente constrangedoras, há escolhas a serem feitas, que se dão a partir de ideias. Desse 
modo, frente às determinações objetivas que constrangem ações, frente às circunstâncias que não são de nossa escolha, ainda assim, para todos esses autores, os homens fazem sua história e o caminho que resolvem trilhar depende em grande parte das imagens que têm do mundo. As ideias, portanto, teriam aquele importante papel causal a que se refere Marc Bloch (2002), isto é, de permitir aos atores sociais fazer escolhas numa situação de incerteza e de opções objetivamente limitadas.

O segundo aspecto não corriqueiro que justifica recorrer a esses três autores refere-se ao fato de que não se limitaram a reconhecer as ideias dos atores sociais como importantes objetos de análise. Mais do que isso, todos mostram-se "vocacionados para a teoria política", segundo a acepção de Wolin (1969), isto é, dedicam-se fundados em particular "estrutura de intenções", da elaboração de extensa crítica a um mundo sistematicamente enviesado; todos identificam processo histórico de longa duração e incontornável: o capitalismo para Marx, a burocratização para Weber e a democratização para Tocqueville. Em todos eles, esses processos têm características sistêmicas, de modo que se torna fundamental pensar as conexões entre as partes que os compõem, seus efeitos sistemáticos e a melhor maneira de evitá-los. Consequentemente, a crítica ao despotismo do capital, à frialdade da dominação burocrática e ao despotismo democrático vem necessariamente acompanhada do elogio à revolução, do reconhecimento do carisma e da política, bem como da necessidade enfática do associativismo e de outras organizações intermediárias como vias de escape três alternativas que apostam e apontam em direção a um mundo em que aqueles efeitos possam ser anulados ou atenuados. Neste sentido, na medida em que as interpretações dos clássicos fizeram (ou tentaram fazer) as vezes de diagnósticos e prescrições para sintomas e crises "no mundo", sua atenção dada à vida coletiva ou sua "preocupação com a 
res publica e a res gestae", como diz Wolin (1969, p. 1078), faz desses autores teóricos "épicos".

É exatamente desse ponto em diante que gostaríamos de explicitar nossa concepção de teoria política e mostrar como informa a definição de teóricos políticos coletivos utilizada neste texto. Para tanto, partimos das contribuições de Sheldon Wolin. ${ }^{3}$ Há ao menos duas concepções de teoria política que permeiam a obra deste autor, na qual encontramos, primeiro, um modelo centrado na ideia de vocação (Wolin, 1969) e, depois, outro baseado na ideia de invocação (Wolin, 2000).

No primeiro, que é a bússola normativa usada por nós para pensar os movimentos sociais como se fossem teóricos políticos, são centrais a diferenciação e o distanciamento em relação à ciência política estadunidense behaviorista, então hegemônica, criticada por Wolin como subteorizada, supostamente neutra e ironicamente chamada de "metodista" ou "metódica" porque era obcecada por questões de método. Contra tal ciência política, ${ }^{4}$ a vocação distintiva da teoria política estaria em seu caráter crítico. Crítica, no primeiro texto de Wolin, tem três significados interligados: primeiramente, toda crítica preocupa-se com questões públicas, segundo, observa tais questões com o objetivo de denunciar o "viés sistematicamente equivocado" da realidade e, por fim, ao fazê-lo, a crítica está voltada para mundos instituídos (sociocultural, econômica e institucionalmente) e não apenas, nem sobretudo, para a teoria. ${ }^{5}$ É essa concepção de

\footnotetext{
3 Ver também Schaar e Wolin (1963).

${ }^{4}$ A rigor, a luta teórica de Wolin não se deu apenas contra a ciência política "metódica"; mas também, em vários outros textos, em oposição àqueles teóricos e filósofos políticos, especialmente L. Strauss e seus seguidores, que ele denominava "moralistas" (Schaar e Wolin, 1963).

${ }_{5}$ Assumimos, contudo, que esse último traço é uma estratégia argumentativa de Wolin, pois "o engajamento político é claramente insuficiente como o principal critério para uma teoria política. É necessário engajar as interpretações rivais no nível teórico com relação a seus valores fundamentais" (Wiley, 2006, p. 221). Em defesa
} 
crítica que nos possibilita pensar movimentos sociais e sua fabricação de ideias e ideais, como "vocacionados" para a teoria política. Para Wolin, a adjudicação "política" da teoria política depende de uma forma público-prática, e não só teórico-filosófica, ${ }^{6}$ de engajamento e tratamento da realidade e de suas potências. "A maior parte das teorias do passado foi informada por uma 'preocupação pública', uma qualidade que não era acessória à atividade, mas fundamental à noção mesma de estar engajado numa teoria política" (Wolin, 1969, pp. 1078-1079, tradução nossa, grifo no original).

É verdade que a concepção woliniana de teoria política passou da vocação à invocação. Se antes o que preocupava o autor era a obsessão metodológica da ciência política behaviorista, ${ }^{7}$ agora é a "hiperteorização" da teoria política que o incomoda. (Wolin, 2000, p. 9). Para o filósofo, nas três décadas que separam os dois ensaios, a teoria política teria se fragmentado, se fechado em congressos e em alguns autores, tendo assim se "normalizado", tornando-se espécie de crítica "sem crise", isto é, uma teoria sobre um mundo supostamente pacífico, sem anomalias nem pontos de inflexão. "É teoria teórica mais que teoria política" (Wolin, 2000, p. 15). Daí então sua passagem de um modelo crítico a outro nostálgico: à teoria política cabe, agora, invocar perdas, derrotas e memórias, se dedicar ao "indigesto", ao "não assimilado". Assim, a invocação não é um modelo das potências e da crítica publicamente mediada como anteriormente, mas um modelo das sobrevivências ${ }^{8}$ - "a tarefa da

de Wolin, podemos dizer que ele encara sim seus rivais teóricos, como dizíamos, os moralistas e os metodistas.

${ }^{6}$ Veja-se, por exemplo, a crítica de Wolin a Rawls e àquilo que lhe falta de "político" (Wolin, 1996, p. 118).

7 Cf. Wolin (2000, especialmente pp. 11-14).

8 Embora não endossemos normativamente esse último modelo de teoria política, é fundamental notar que ele é congruente com sua ideia de "democracia fugitiva". Cf. "Democracy needs to be reconceived as something other than a form of government: as a mode of being which is conditioned by bitter experience, doomed to 
teoria política pode ser invocar o que foi derrotado, mas não desapareceu totalmente" (Frank e Tamborino, 2000, p. 16, tradução nossa).

Mais do que adesão à primeira concepção de teoria política, é o contraste entre os modelos crítico e nostálgico que nos permite explicitar em que sentido é possível definir os movimentos sociais qua teóricos políticos coletivos. A analogia entre movimentos sociais e um modelo crítico do que é teoria política certamente não estabelece relação de identidade entre eles. Movimentos sociais e teoria política não se equivalem pela seguinte razão: a teoria política opera num plano distinto, isto é, no plano do debate teórico-normativo e da reflexão sistemática. Os movimentos sociais, ao contrário, tal como outros atores políticos, atuam no âmbito da ação, da fortuna e da luta política.

Trata-se, então, de pensar em que medida movimentos sociais produzem, em seu devido plano (i.e., o da luta e da ação prática), "teoria política", tal como definida pelo primeiro Wolin (1969). As propriedades e continuidades entre os planos específicos dos movimentos sociais e da teoria política ilustram a adequação desse exercício de abstração. Por exemplo: ideologias políticas constituem o leque de ideários no qual ambos, teorias e movimentos, se inspiram. Porém, assim como as ideologias pautam os movimentos sociais sem determinar sua ação, analogamente esse leque de inspiração tampouco faz que o debate teórico-político seja reduzível à ideologia (Freeden, 2006, p. 8). Interessantemente, ideologias podem ser objetos de análise no caso da teoria política e de luta no caso dos movimentos sociais. Podem ser também objeto de crítica em ambos. De outra perspectiva, a temporalidade própria a cada um desses planos impõe demandas e problemas que exigem respostas imediatas, no

succeed only temporarily, but is a recurrent possibility as long as the memory of the political survives" (Wolin, 1994, p. 23). 
caso dos movimentos sociais, e reflexivas, no caso da teoria política. Enquanto a urgência imposta por determinadas situações dramáticas vividas pelos atores dos movimentos sociais obedece à lógica contextual da ação e da fortuna, o contexto da reflexão teórica é quase sempre acadêmico e vagaroso. O contraste com o segundo Wolin (2000) mostra exatamente isso: não pressionado por algo já em disputa, ou cujo desenrolar não é urgente e pode ser postergado, o teórico nostálgico pode, em seu devido tempo, invocar perdas e sobrevivências sem estar pressionado pela dramaticidade da luta. Tomando a teoria política nesses termos, evidentemente movimentos sociais não podem ser definidos como teórico-políticos. No entanto, como conjuntos de atrizes e atores que produzem ideias no momento em que agem publicamente, os movimentos sociais partilham com a teoria política a vocação da crítica ao viés sistemático encontrado no contexto em que atuam. São, nesse sentido, "autores em ação” e, por conseguinte, teóricos políticos coletivos.

\section{O lugar das ideias na literatura contemporânea}

Como ambas características presentes nos trabalhos dos autores clássicos discutidos anteriormente foram atualizadas pela literatura contemporânea que se dedicou a pensar o impacto das ideias na política? A nosso ver, essa literatura representou, ao mesmo tempo, avanço e retrocesso. Onde reside avanço e onde se encontra retrocesso é o que este item pretende discutir.

A literatura da "virada ideacional" avançou na discussão sobre o impacto das ideias ao contribuir para maior precisão em três dimensões importantes. A primeira refere-se à apresentação de garantias de que ideias possam de fato ser consideradas como variáveis explicativas de direito próprio, algo inseparável da identificação de procedimentos metodológicos e comprobatórios específicos. A segunda dimensão refere-se à produção de definição mais precisa e refinada 
do que são ideias e dos seus impactos. Por fim, outro avanço reside na explicitação das condições de viabilidade das ideias, isto é, na identificação das circunstâncias que lhes permitem produzir efeitos sobre outcomes políticos.

No que diz respeito ao primeiro ponto, o ponto de partida consiste em estabelecer princípios básicos de uma "teoria ideacional" como teoria causal. Isso significa que "O traço distintivo de uma teoria ideacional é que [os] objetivos e crenças [dos atores sociais e políticos] podem variar independentemente das condições objetivas materiais, gerando diferentes decisões" (Jacobs, 2015, p. 7). Se uma teoria ideacional não conseguir fazer isso, então, na verdade, estamos na presença de uma "explicação materialista”. Portanto, qualquer teoria ideacional deve mostrar três tipos de evidências: primeiro, que os decisores possuem crenças particulares; segundo, que as crenças modelam suas escolhas; e, por fim, que suas crenças não são redutíveis 242 às condições materiais da situação de escolha. A melhor maneira de fazer isso é juntar diacronia com comparação. Como diz Sheri Berman (1998, pp. 33-34), é preciso mostrar que um mesmo ator fará escolhas similares ao longo do tempo, mesmo quando enfrenta mudanças contextuais, e comprovar que atores diferentes tomam decisões distintas frente a condições similares.

No entanto, a operacionalização de uma teoria ideacional exige clara definição do que se entende por ideias, condição necessária para adequada descrição da configuração ideacional que se pretende analisar. Do que se fala, afinal de contas, quando temos em mente as ideias de um grupo social, de um conjunto de atores políticos ou de líderes de dada organização? Quando se trata de discutir esse ponto, os autores da virada ideacional procuram diferenciar as ideias por sua abrangência e capacidade estruturante, como sintetiza o quadro a seguir elaborado por Campbel (1998). 
Quadro 1

Dimensões e constrangimentos ideacionais

\begin{tabular}{c|c|c}
\hline \multirow{2}{*}{ Constrangimentos } & \multicolumn{2}{|c}{ Dimensões } \\
\cline { 2 - 3 } & $\begin{array}{c}\text { Conceitos de primeiro } \\
\text { plano } \\
\text { (foreground concepts) }\end{array}$ & $\begin{array}{c}\text { Pressupostos de } \\
\text { fundo (background } \\
\text { assumptions) }\end{array}$ \\
\hline Nível cognitivo & Programas & Paradigmas \\
\hline Nível normativo & Enquadramento & Sentimentos públicos \\
\hline
\end{tabular}

Fonte: Campbell (1998).

Background descreve pressupostos infraconscientes que habitam o pano de fundo dos debates políticos, delimitando-lhes; o foreground descreve as ideias usadas e articuladas estrategicamente pelos atores envolvidos direta e indiretamente nas lutas políticas. Constrangimentos podem ser normativos, isto é, quando ideias se constituem em valores e atitudes que diferenciam o certo do errado, legitimando determinadas formas de pensar e estigmatizando outras; constrangimentos também podem ser de natureza cognitiva, isto é, quando conceitos culturalmente dados são operacionalizados para autorizar determinadas soluções de problemas específicos e para desautorizar outras.

Portanto, de acordo com o quadro, paradigmas e programas são constrangimentos cognitivos que definem, em dimensões distintas, maneiras socialmente aceitas de resolver problemas. No caso de paradigmas, pressupostos de fundo, internalizados pelos agentes em processos de socialização de longa duração, limitam o elenco de soluções que os atores tendem a perceber como adequadas; no caso dos programas, trata-se de prescrições precisas de políticas públicas mobilizadas estrategicamente na luta política e que, autorizadas por paradigmas, facilitam a ação entre tomadores de decisão para definir como resolver um problema específico de política pública (Campbell, 1998). Sentimentos públicos e enquadramento são, por sua vez, 
constrangimentos normativos que impõem distinções entre o certo e o errado, e que também operam em dimensões distintas. Sentimentos públicos são pressupostos normativos de fundo, internalizados, que legitimam ou deslegitimam, que autorizam ou desautorizam, enfim, que tornam determinados temas aceitáveis ou inaceitáveis ao público. Fornecem, assim, base extrainstitucional ou, se se quiser, cultural da legitimidade política. Enquadramento refere-se a um modo de, na luta política, apresentar estrategicamente certos programas e soluções com vistas a torná-los compatíveis com o sentimento público dominante e, assim, legitimá-los perante a população. A luta política deve ser entendida, portanto, como embate permanente de enquadramento e contraenquadramento (Campbel, 1998; Hay, 1996). É claro que esses constrangimentos e dimensões estão interligados. Como diz Campbel (1998, p. 385), "paradigmas e sentimentos públicos são conceitos de segunda 244 ordem na medida em que se constituem em ideias subjacentes sobre as quais os conceitos de primeira ordem, isto é, programas e enquadramentos, baseiam-se respectivamente".

Por fim, o avanço propiciado por essa literatura aponta para a identificação das circunstâncias que, uma vez presentes, aumentam a potencialidade de impacto nas decisões políticas. Esse ponto é importante, pois os autores da virada ideacional, ao defender a autonomia explicativa das ideias, não pretendem propugnar por uma perspectiva ingenuamente idealista. Se, por um lado, as ideias contam como variável autônoma na explicação das preferências dos atores políticos, estas só se viabilizam na presença de determinadas condições. Assim, afirmam categoricamente que ideias nunca operam sozinhas e que a presença de certas condições políticas e institucionais são fundamentais para que possam produzir efeitos sobre o mundo político. Em geral, identificam-se três condições de viabilidade. A primeira refere-se a condições propriamente ideacionais, isto 
é, uma ideia será tanto mais poderosa quanto mais vinculada à tradição ideacional prévia que cria path dependence ideacional. A segunda condição de viabilidade diz respeito à recepção da ideia em questão por instituições com capacidade decisória. Por fim, toda ideia precisa ancorar-se numa coalizão política, precisa encontrar seus carriers (Berman, 1998), seus political entreprenuers (Kingdon, 2014), agentes dispostos a defender tais ideias, inseridos numa coalizão que dê sustentação a suas atividades. Com relação a este último ponto, é importante observar a existência de dialética entre ideias e coalizões, pois se estas são condições de viabilidade política das ideias, aquelas, por sua vez, também aumentam as chances de uma coalizão se formar (Gourevitch, 1986).

$\mathrm{O}$ avanço, portanto, sintetiza-se nesses três pontos: epistemológico/metodológico, conceitual e contextual. Onde reside, então, o retrocesso protagonizado por essa literatura quando comparada às análises clássicas? Para usar a expressão de Wolin (1969), os autores da virada ideacional dedicaram-se inteiramente à vita methodica. Ou seja, orientados por uma preocupação estritamente científica, dedicaram-se basicamente a questões referentes à operacionalização das proposições causais da teoria ideacional, tal como descrita no início deste item. Como contrapartida dessa hipertrofia metodológica houve atrofiamento da perspectiva teórica. Dito de outra maneira, houve completo abandono da vocação para a teoria política e, por conseguinte, não encontramos nesses autores qualquer tentativa mais ousada de formular diagnósticos sistemáticos e abrangentes sobre sistemas sociais. Ao contrário, as pesquisas giram sempre em torno de assuntos muito específicos relativos a áreas decisórias muito delimitadas (política de saúde, política econômica, política social etc.). Nesse sentido, o desenvolvimento científico sobre a força das ideias se mostrou incompatível com a produção de uma teoria normativa sobre a política. Seria possível fugir a essa antinomia? 
No item seguinte esboçamos uma resposta a esta questão. Pretendemos mostrar, por meio da análise da luta feminista no Paraguai, que os movimentos sociais conjugam atividades cognitivas importantes. Ao mesmo tempo em que formulam propostas concretas para a supressão ou atenuação de problemas concernentes à vida das mulheres naquele país (representação política escassa, violência doméstica, falta de assistência à saúde etc.), elaboram crítica sistemática ao viés de gênero da sociedade e do sistema político paraguaios e, por conseguinte, uma proposta de superação desse mesmo viés. É esse triplo movimento - formulação de políticas públicas, proposição de crítica sistêmica e apresentação de projeto alternativo - ${ }^{9}$ que nos leva a caracterizar os movimentos sociais analisados não apenas como "portadores de ideias" razoavelmente eficazes (como sugere a literatura da virada ideacional), mas também como teóricos políticos (nos termos de Wolin).

\section{0 lugar do 'gênero' nas políticas: feminismos, alianças e contraenquadramento no Paraguai}

As dinâmicas de interação socioestatal pelas quais partes do Executivo paraguaio foram permeadas pela "perspectiva de gênero" transcorreram no contexto de transição e democratização do Paraguai que marcou a década de 1990, após a deposição do general Alfredo Stroessner em 1989. Grosso modo, esse processo de generificação (Szwako, 2012), ou gender mainstreaming, passou por três momentos-chave na incorporação e difusão do "enfoque de gênero" pelo Estado paraguaio. O primeiro deles é a gênese da Secretaria da Mulher, órgão com estatuto ministerial, criada em 1993 em boa medida como forma de articulação entre a então recém-empossada Ministra com uma fração do feminismo

\footnotetext{
9 A separação entre esses três movimentos é puramente analítica. A generificação das políticas públicas, discutida a seguir, é inseparável de uma crítica ao viés de gênero da sociedade paraguaia e de um projeto normativo alternativo.
} 
paraguaio distinguida por sua verve partidária, a então 'Multisectorial de Mujeres'. O segundo momento importante na generificação estatal paraguaia se deu ao redor da "IV Conferência Mundial da Mulher" ocorrida em Pequim, em 1995, que serviu como oportunidade internacional para as demandas de organizações e ativistas da mais antiga articuladora civil feminista do país, a Coordenação de Mulheres do Paraguai (CMP). Já o terceiro momento abarca o período posterior ao mês de março de 1999, quando eclodiu o chamado Marzo paraguayo - violento ciclo de protestos disparado pelo assassinato do então vice-presidente do Paraguai, cujo confronto entre manifestantes e forças repressivas levou à morte de oito daqueles primeiros. Após 1999, uma vez normalizado o pacto político no seio das elites e partidos paraguaios, a incorporação da "categoria de gênero" deu vez à institucionalização com essa ideia, passando a permear e a estruturar diversas partes e agências do Estado paraguaio, por certo, não restritas ao Poder Executivo.

Embora a IV Conferência Mundial da Mulher tenha sido catalisador das energias feministas e das dinâmicas de generificação estatal pelo mundo, a elaboração de um ideário ao redor da categoria "gênero" por parte das militantes e organizações feministas paraguaias data de antes de 1995. Um dos primeiros episódios no qual se vê a ideia de "gênero" conformando o imaginário e a ação feministas no Paraguai pode ser visto em Hacia una presencia diferente. Mujeres, organización y feminismo (Echauri et al., 1992). Nesse livro, as feministas pesquisadoras do Centro de Documentación y Estudios - renomada ONG fundadora da CMP e com ampla atuação na sociedade civil paraguaia - produzem uma espécie de memória "da luta das mulheres" no país; para tanto, elas dizem, "é preciso analisar tanto a pratica das mulheres organizadas como a das individualidades [...] que fizeram muito pelo avanço da consciência de gênero em nosso país" (Echauri et al. 1992, p. 3, tradução nossa). Nesse resgate, sua 
divisão metodológica classifica aqueles grupos ou organizações de mulheres que "se caracterizam pela incorporação de elementos de gênero na sua prática" e aquelas que, "sem negar a existência da discriminação feminina, [na] sua prática não incorpora $[\mathrm{m}]$ elementos de género" (Echauri et al. 1992, p. 12, tradução nossa). Como o ideário feminista não coincide com a totalidade das organizações de mulheres, elas distinguem o feminismo não só como movimento, mas também como postura. "Por um lado, o termo feminismo designa uma postura determinada diante da situação da mulher na sociedade e, por outro, se refere a um movimento social baseado em reivindicações de gênero" (Echauri et al. 1992, p. 61, tradução nossa). Feminismo e 'gênero' são aí associados:

O feminismo pode ser definido com base em três características: [a] reconhecimento da discriminação social da mulher; [b] identificação da base cultural e ideológica, não natural, dessa discriminação; [c] elaboração de propostas e ações concretas para transformar a situação de discriminação. (Echauri et al. 1992, p. 61, tradução nossa)

Enquanto a última parte desta citação nos fala de gender mainstreaming, a segunda nos remete ao núcleo distintivo do conteúdo da ideia de gênero, isto é, ao caráter não biológico das diferenças e desigualdades entre homens e mulheres. Embora tal ideia pareça bastante simples, como veremos adiante, uma vez tendo conquistado espaço normativo, ela causou, desde Pequim, fortes reações e pânicos.

A trajetória da ideia de "gênero" rumo a sua incorporação em políticas públicas segue o ritmo das interações travadas entre militantes do feminismo paraguaio e autoridades executivas. Embora não haja espaço para maior desenvolvimento empírico, vale notar que, tal como em outras dinâmicas nacionais, a IV Conferências Mundial da Mulher 
operou como espécie de ponte articuladora entre Estado e sociedade civil, neste caso, entre as feministas da CMP e a Secretaria da Mulher fundada anos antes. Isto posto, vejamos dois outros episódios nos quais a ideia de "gênero" é publicamente acionada e disputada, "generificando", por assim dizer, normativas do Executivo paraguaio.

O "Plan Nacional de Salud Reproductiva" traz em seu nome a marca da década das conferências, com seu subtítulo "versão pós-Cairo". ${ }^{10}$ Datado de 1997, incorpora "gênero" entre seus "eixos" e "mudanças fundamentais":

Além dos aspectos populacionais, de mortalidade, de fertilidade (visão da demografia); [o Plano] incorpora a consideração da "qualidade de vida", com ênfase na satisfação das necessidades de homens e mulheres como indivíduos, do direito das pessoas, da equidade social e de gênero. (Paraguay, 1997, p. 1, tradução nossa)

$\mathrm{Na}$ raiz desse caso de generificação estatal se nota a presença de Kuña Aty, 11 organização feminista que então compunha a CMP. Ao lado dela, na "elaboração e revisão" do Plan, estão outras organizações civis, agências do sistema internacional e de ajuda internacional, bem como organismos governamentais. Visto na trajetória das ações institucionais já existentes, tal Plan reformula e se sobrepõe a programas anteriores, pois se 'atualizam os conceitos para a fundamentação teórica do Plan'. É então por via cognitiva que se incorpora a 'perspectiva de gênero'. Segundo o Plan,

${ }^{10}$ Cf. "Se denomina así al presente Plan, pues se caracteriza por considerar como eje, los cambios sustanciales que se han dado en la Conferencia Internacional sobre Población y Desarrollo del Cairo (1994) y la Plataforma de Acción de Beijing (1995)" (Paraguay, 1997).

11 Tendo atuado por mais de duas décadas, a Fundação Kuña Aty (reunião ou lar de mulheres, em guarani) foi a ONG liderada pela feminista histórica Gloria Rubin, Ministra da Mulher entre 2008 e 2013. A ONG foi referência no país na proteção e atendimento de mulheres vítimas de violência, seja física, sexual ou outra. 
A perspectiva de gênero nos permite identificar papeis, socialmente atribuídos a homens e mulheres, que impõem estereótipos e impedem o pleno desenvolvimento do potencial dos indivíduos. Nesse sentido, o enfoque de gênero permite a identificação de características socialmente construídas que definem e estabelecem limites para as tarefas femininas e masculinas a partir da construção de símbolos, imagens e representações, normas, padrões institucionais e elementos identitários subjetivos que distinguem os sexos e que pretendem justificar, com isso, as relações diferenciadas sobre o aproveitamento e uso dos recursos sociais. (Paraguay, 1997, p. 15, tradução nossa)

As seguintes edições do Plan mantiveram "gênero", embora com mudanças parciais. Em suas duas versões mais recentes (2009-2013 e 2014-2018), "gênero" permanece como ideal que dá enquadramento mais amplo pautando 250 os respectivos objetivos estratégicos. Enquanto a versão de 2009 inova falando de "participação social", na última versão o objetivo estratégico incorpora originalmente a ideia de "interculturalidade". Em ambos, a ideia "gênero" muda de status de modo a ultrapassar o nível normativo para ser aproximado das causas de fenômenos violentos e das ações contra eles: em 2009 a "Prevenção e atenção a pessoas em situação de violência intrafamiliar e violência baseada em gênero" é um "âmbito" do Plan, para tornar-se “área estratégica” na versão de 2014.

A despeito dessa continuidade normativa observada na trajetória do "gênero" no Plan, sua falta de capacidade de enforcement tem deixado insatisfeitas as organizações feministas, de direitos humanos e de direito à saúde, que reivindicam que

[o] Estado deveria incluir entre suas prioridades o cumprimento dos planos, políticas e programas de saúde 
que já incorporaram o conceito de direitos sexuais e direitos reprodutivos, de modo a garantir [...] em particular para mulheres, meninos e meninas, o acesso a serviços básicos de saúde, a fim de reduzir as altas taxas de mortalidade materna e infantil. (Coordinadora de Derechos Humanos del Paraguay, 2003, pp. 464-465, tradução nossa)

Reivindicação análoga a essa ressoa em um mecanismo internacional aberto à crítica das militantes feministas; para elas, "el acceso a servicios de atención a la salud de la mujer, y en particular de la salud sexual y reproductiva, constituye la esfera de mayor inequidad y un signo de clara exclusión de las mujeres" (Comité de América latina y el Caribe para la Defensa de los Derechos de la Mujer; Coordinación de Mujeres del Paraguay; Centro de Documentación y Estudios, 2005, p. 33$).{ }^{12}$

Embora esforço conjunto entre feministas, burocratas do Ministério da Saúde e agências do sistema internacional tenha pretendido e, eventualmente, logrado combater tais limitações na política de saúde sexual e reprodutiva publicamente denunciadas pelas organizações civis, houve forte contraenquadramento para barrar a generificação. Porém, em seus debates e embates contra grupos religiosos fundamentalistas antidireitos, as feministas queriam mais que um 'plano', queriam a aprovação de um anteprojeto de "Lei de saúde sexual, reprodutiva e materno-perinatal". Mas, em uma década de luta, permanecem "projetos de lei trabalhados há vários períodos legislativos que foram rechaçados, por oposição de setores conservadores, ou nem sequer foram apresentados, como o [e.g., o projeto] da lei de saúde

12 Conhecida por sua sigla CEDAW, a Convenção das Nações Unidas para a Eliminação de Todas as Formas de Discriminação contra a Mulher é um instrumento que compele, por meio de seu Comitê, sem força vinculante, porém ao modo de sugestão e crítica, os Estados-parte a prestar conta de seus esforços e iniciativas no fortalecimento dos direitos humanos das mulheres. 
sexual e reprodutiva, e materno perinatal" (Montórfano, 2015, p. 152, tradução nossa). Passemos, por fim, à segunda política pública, se não norteada, permeada pela ideia de "gênero" e pelas interações pró e contra ela.

Promulgada em 2000, a "Ley contra la violência doméstica”, doravante Lei $\mathrm{n}^{\mathrm{o}} 1.600$, estabelece as normas e medidas de proteção relativas à

pessoa que sofra lesões, abuso físico, psicológico ou sexual, por parte de um dos membros do grupo familiar, que inclui o originado pelo parentesco, no matrimônio ou na união de fato, mesmo que a coabitação tenha cessado, também no caso de casais não cohabitantes e de filhos, sejam ou não comuns. (Paraguay, 2000, artigo $1^{\circ}$, tradução nossa)

Embora não seja possível refazer sua trajetória legislativa, é ponto pacífico no feminismo paraguaio o peso das organizações e militantes da CMP, bem como de sua aliança com a então Ministra da Secretaria da Mulher, num esforço de dois anos entre a formulação do anteprojeto de lei e da sua aprovação. De modo interessante, como que contornando quaisquer eventuais oposições, este instrumento não fala propriamente em "violência de gênero", mas em "violência doméstica", elencando em seus artigos as instituições estatais responsáveis por acolher denúncias, proteger vítimas e punir agressores.

Em sua avaliação dos cinco anos pós-Pequim, ${ }^{13}$ as feministas da CMP consideravam a Lei n⿳0 1.600 um "avanço legal”, mas com a seguinte reserva: "as maiores dificuldades estão vinculadas à escassez de investigações sobre o tema, ao registro dos casos de violência e, especialmente, à aplicação das medidas jurídicas para levar adiante as denúncias"

13 Cf. "Implementación de la Plataforma de Beijing en Paraguay 1995-2000. Informe no Gubernamental” (Coordinación de Mujeres del Paraguay, 2001). 
(Martínez, 2001, p. 72). ${ }^{14}$ Basicamente, o Estado paraguaio contava com uma lei contra a violência doméstica, mas não tinha infraestrutura de proteção afinada ao instrumento sensível a tal forma de violência; quer dizer, embora detivesse capacidade jurídica, faltavam-lhe capacidades cognitivas e técnico-administrativas correlatas e necessárias à consecução daquela lei.

Ao mesmo tempo em que seguiram com suas formas de investigação sobre a "violência doméstica e intrafamiliar" (Soto, González e Elías, 2003), e com seus espaços de cuidado e apoio psicológico e jurídico a mulheres, as feministas paraguaias forjaram pontes e arenas de interação com funcionários públicos e, especialmente, com operadores de justiça e polícia para dar conta de tal limitação cognitiva. Duas formas pelas quais as feministas tentaram dar conta desse déficit foram: o "Manual de la Ley 1.600/2000. Explicación y aplicación” (Rivarola, 2002), desenvolvido pela advogada feminista Clara Rosa Gagliardone Rivarola, bem como o "Guía de capacitación 'Género, acceso a la justicia y violência contra las mujeres' para operadores y operadoras de justicia" (Comité de América Latina y el Caribe para la Defensa de los Derechos de la Mujer, 2008), elaborado por Cladem-Paraguay em aliança com agências do Judiciário e do Executivo, bem como apoio de organizações civis e do sistema internacional. Em ambos, é central a concepção de capacitar e sensibilizar operadores e operadoras de Justiça para nuances e complexidades das relações de gênero, violência e família.

O ritmo da generificação estatal relativamente às políticas de combate à violência contra mulheres seguiu caminho consistente, apesar de tortuoso. A mais recente inovação institucional nesta questão foi a "Ley de protección integral a las

${ }^{14}$ Crítica similar aparece no relatório anual da Codehupy, importante articuladora civil paraguaia de organizações de defesa dos direitos humanos; ver Martínez e Santaella (2002, p. 148). 
mujeres, contra toda forma de violência" (Paraguay, 2016), também conhecida no país como a "Ley por Ellas". Sua principal contribuição é a tipificação da noção de "feminicídio" ou de "violência feminicida". A primeira versão do anteprojeto desta lei foi proposta, em 2012, pelo então recém-criado Ministério da Mulher e por sua Ministra, Gloria Rubin. Com a dupla concepção de dar enfoque global ao fenômeno e tipificar o feminicídio, ${ }^{15}$ a proposta de 2012 foi duramente criticada e rejeitada por militantes feministas e também pelas câmaras do Poder Legislativo. ${ }^{16}$ Em 2014, modificado com contribuições feministas, o anteprojeto é reapresentado por Rocio Casca, deputada aliada e presidenta da Comissão de Gênero da Câmara dos Deputados, sendo desta vez criticado tanto

por legisladoras e legisladores como por parte de setores [...] relacionados a grupos conservadores e de igrejas.

Os principais pontos em questão se referem à inclusão da palavra gênero [...] e a alguns tipos de violência como [...] a violência feminicida (González, 2015b, p. 408, tradução nossa).

A versão aprovada ao final de 2016 ficou sem menção a "gênero". Neste sentido, a trajetória legislativa da Ley por Ellas está inscrita numa linha de vitórias parciais do conservadorismo naquele país. ${ }^{17}$ Vitória das organizações e alianças do movimento fundamentalista cujo enquadramento tem tentado fazer da ideia de "gênero" uma "ideologia" (uma suposta "ideologia de gênero" ${ }^{18}$ e cujos resultados e esfor-

\footnotetext{
15 Uma das raízes intelectuais dessa figura jurídica no país é a própria Rubin; veja Rubin e Maciel (2005).

16 Cf. González (2015a, p. 75).

17 Cf. Negrete (2015, p. 73).

18 Para uma das raízes latino-americanas intelectuais da ideia de "ideologia de gênero", ver Revoredo (2004).
} 
ços chegaram, naquele mesmo ano, à proposta de uma "bancada parlamentar pela vida e pela família". ${ }^{19}$ Essa vitória foi, porém, parcial. Se a ideia de "gênero" não permeou a lei, as feministas conseguiram, nas disputas textuais e discursivas travadas nas antessalas legislativas com apoio de suas aliadas e frente ao contraenquadramento, emplacar seus ideais tirando da Ley por Ellas medidas de proteção de lógica familista e revitimizante, típica das medidas de viés conciliador. ${ }^{20}$ Tortuosa, a generificação segue como processo e como desafio.

\section{Movimentos sociais como teóricos políticos}

Este artigo tentou aproximar as discussões de teoria política e políticas públicas. Procuramos mostrar de início que os autores clássicos fizeram, cada um a seu modo, essa conjugação. Neles, a análise do impacto das ideias na vida política articulou-se com a crítica às patologias da vida coletiva, da qual derivavam projetos sociais alternativos. Vimos, em seguida, como a literatura contemporânea dedicada ao impacto das ideias nas políticas, ao ganhar em acuidade analítica e precisão metodológica, perdeu em alcance normativo. Por fim, a título de conclusão, vamos mostrar, com base na generificação das ações estatais vistas, como seria possível conjugar novamente políticas públicas e teoria política pensando movimentos sociais não só como portadores de ideias, mas também como teóricos políticos.

Vimos que a trajetória intelectual da noção de "gênero" remete, antes de Pequim, 1995, ao núcleo das demandas feministas frente ao Estado paraguaio. No entanto, tal como boa parte das demandas dos movimentos sociais, essa demanda não se esgota em si; ganha, antes, significado e

\footnotetext{
19 Ver <www.diputados.gov.py/ww1/noticia-fb.php?id=15818>. Acesso em: 10 set. 2017.

${ }^{20}$ Segundo Mirta Moragas, militante da CMP, a quem agradecemos pela entrevista.
} 
força dentro de enquadramento ideacional que disputa os vetores e sentidos de sentimentos públicos mais amplos, para retomar Campbell (1998). Neste sentido, a elaboração de demandas dos movimentos sociais assume, no mínimo, duas funções: de produção de conhecimento e de diagnóstico-prognóstico simultâneo de patologias sociais. Primeiramente, o investimento feito ao redor de uma demanda específica (neste caso, incorporação e institucionalização da "perspectiva de gênero" nas políticas públicas) organiza um complexo "conhecimento político tácito" (Wolin, 1969, p. 1.070). Quer dizer, qua teóricos políticos coletivos, ativistas e organizações do movimento racionalizam esses "saberes tácitos" produzindo mais conhecimento. Seguindo as pistas empíricas até aqui arroladas, podemos afirmar que o conhecimento aí produzido opera como um continuum cujos polos vão da tematização à sistematização, interpondo vivência concreta e dados sistematizados. Num 256 polo, a experiência vivida (neste caso, por mulheres) é a base a partir da qual se tematiza, se desprivatiza e se critica aquela realidade vivida. Noutro polo, dão-se a produção e o acúmulo de informação sobre realidades e dramas populacionais, ou de segmentos da população, dispersos no território (e.g., "El Señor es contigo") - produção e acúmulo de dados que servirão como fonte alternativa de conhecimento e luta para outros agentes e discursos.

Já o caso das leis de combate à violência contra mulheres é exemplar de como essas atrizes organizadas produzem, parafraseando Wolin (1969), uma teoria política nativa, dissecando partes patológicas da realidade e tornando inteligível nelas um viés sistematicamente equivocado ao mesmo tempo em que se opõem a ele. Lida e reconhecida pelo potencial inscrito no ideário dos movimentos em luta, uma demanda disputada e eventualmente institucionalizada não se resume à conquista institucional, pois são ambas, demanda e conquista, pistas da luta política e simbólica 
deflagrada no âmbito mais estruturante daqueles sentimentos públicos, e contra ele (González, 2015a). Nestes termos, machismo, heterossexismo e uma cultura patriarcal militarista são sentimentos públicos paraguaios. Ao fazer sua crítica prática, as feministas demandam que o Estado paraguaio fale em termos de "gênero", que seus funcionários, secretarias e ministérios atuem, com base em suas leis e políticas, a partir dessa categoria e, consequentemente, "criem" uma nova realidade social e política: diagnóstico e prognóstico andam juntos.

Se, como vimos, o ritmo da generificação estatal no Paraguai segue constante, apesar de tortuoso, as dinâmicas de circulação de pessoas, ideias e ideais entre sociedade civil e Estado viram no abreviado governo Lugo (2008-2012) uma intensificação das interações socioestatais e aumento relativo da permeabilidade estatal. No contexto daquele governo, o aparente e provável incremento das dinâmicas de generificação de políticas e ministérios, a começar pelo nome de Gloria Rubin, deixou o contramovimento religioso em pânico. É certo que entre a demanda feminista por generificação e a institucionalização dessa ideia há um grau considerável de tradução e refração, quer dizer, bastante do que se designa por "gênero" numa voz civil é transformado e adaptado institucionalmente em política pública. No entanto, a despeito desse $g a p,{ }^{21}$ o contramovimento religioso tem investido quantum expressivo de energia, recursos e argumentos não só para frear a agenda da generificação, mas também para fazer da demonização dessa agenda sua principal arma de confecção de pânicos com efeitos políticos regressivos (Szwako, 2014).

Nesse sentido, não há como não perguntar: seria adequado tratar também as organizações, militantes e

${ }^{21}$ As determinantes e as mediações desse gap ideacional entre o demandado e o instituído constituem, a nosso ver, objeto fundamental da agenda de pesquisa sobre o impacto das ideias nas políticas e na luta política. 
parlamentares do movimento religioso anti-'gênero' como teóricos políticos coletivos? Pensamos que sim. Sua mais recente bancada, por exemplo, é um "método de luta contra a pressão internacional a favor da ideologia de gênero e o aborto". No seu contraenquadramento, a suposta "ideologia de gênero" é um "antivalor", pois um imaginado "sistema internacional" apoia o "lobby gay" que fere "princípios". É um dos sentimentos públicos mais caros à autoimagem paraguaia, ameaçado, segundo essa visão, pela generificação das políticas públicas; o Paraguai de história idealizada e bélico ressoa na voz da reação, defensora de um modelo limitado e limitante de "família". ${ }^{22}$ De um lado, esse investimento todo denota, a despeito das limitações de várias ordens e para além dos casos de violência e saúde sexual e reprodutiva, a força com que a ideia de "gênero" vem se cristalizando nas formas estatais de classificação e ordenação do mundo. De outro, permite dar resposta afirmativa àquela questão: sim, 258 os movimentos anti-'gênero' produzem também suas teorias políticas nativas, nas quais o status quo é naturalizado e os direitos humanos, desprezados. Portanto, mais que conservadores, são teóricos políticos da reação.

\section{Renato Perissinotto}

é Professor Associado do Programa de Pós-Graduação em Ciência Política (UFPR) e pesquisador CNPQ.

\section{José Szwako}

é Professor Adjunto do Instituto de Estudos Sociais e Políticos (IESP-UERJ).

\section{Bibliografia}

BÉLAND, D. 2005. Ideas and social policy: an institutionalist perspective.

Social Policy and Administration, v. 39, n. 1, pp. 1-18.

${ }^{22}$ Ver <www.diputados.gov.py/ww1/noticia-fb.php?id=15818>. Acesso em: 10 set. 2017. 
2009. Ideas, institutions, and policy change. Journal of European

Public Policy, v. 16, n. 5, pp. 701-718.

. 2010. The idea of power and the role of ideas. Political Studies

Review, v. 8, n. 2, pp. 145-154.

BÉLAND, D.; HACKER, J. S. 2004. Ideas, private institutions and

American welfare state "exceptionalism": the case of health and old-age

insurance, 1915-1965. International Journal of Social Welfare, v. 13, n. 1,

pp. $42-54$.

BERGER, P. L.; LUCKMANN, T. 1994. A construção social da realidade:

tratado de sociologia do conhecimento. Tradução de Floriano de Souza

Fernandes. Petrópolis: Vozes.

BERMAN, S. 1998. The social democratic moment. London: Harvard

University.

2001. Ideas, norms, and culture in political analysis. The Journal of

Comparative Politics, v. 33, n. 2, pp. 231-250.

. 2013. Ideational theorizing in the social sciences since 'Policy

Paradigms, Social Learning, and the State'. Governance: An

International Journal of Policy, Administration, and Institutions, v. 26, n. 2, pp. 217-237.

BLOCH, M. 2002. Apologia da história ou o ofício do historiador. Tradução de André Telles. Rio de Janeiro: Jorge Zahar.

BLYTH, M. 1997. "Any more bright ideas?” The ideational turn of comparative political economy. Comparative Politics, v. 29, n. 2, pp. 229-250.

. 2001. The transformation of the Swedish model: economic ideas, distributional conflict, and institutional change. World Politics, v. 54, n. 1, pp. 1-26.

2002. Great transformations: economic ideas and institutional change in the twentieth century. Cambridge: Cambridge University.

2003. Structures do not come with an instruction sheet: interests, ideas, and progress in political science. Perspectives on Politics, v. 1, n. 4, pp. 695-706.

BUTLER, J. 2015. Introdução. In: LUKÁCS, G. A alma e as formas.

Tradução de Rainer Patriota. Rio de Janeiro: Autêntica, pp. 11-28.

CAMPBELL, J. L. 1998. Institutional analysis and the role of ideas in political economy. Theory and Society, v. 27, n. 3, pp. 377-409.

CHARTIER, R. 2003. Origens culturais da Revolução Francesa. Tradução de

Chris Schlesinger. São Paulo: Unesp.

COMITÉ DE AMÉRICA LATINA Y EL CARIBE PARA LA DEFENSA DE

LOS DERECHOS DE LA MUJER - CLADEM. 2008. Guía de capacitación 
“Género, acceso a la justicia y violencia contra las mujeres” para operadores y operadoras de justicia. Asunción: Cladem.

COMITÉ DE AMÉRICA LATINA Y EL CARIBE PARA LA DEFENSA DE LOS DERECHOS DE LA MUJER - CLADEM; COORDINACIÓN DE MUJERES DEL PARAGUAY - CMP; CENTRO DE DOCUMENTACIÓN Y ESTUDIOS - CDE. 2005. Informe Sombra CEDAW: vigilancia ciudadana sobre los derechos humanos de las mujeres en Paraguay. Asunción: Cladem, CMP, CDE.

COORDINACIÓN DE MUJERES DEL PARAGUAY - CMP. 2001.

Implementación de la Plataforma de Beijing en Paraguay 1995-2000. Asunción: CMP.

\section{COORDINADORA DE DERECHOS HUMANOS DEL PARAGUAY}

- CODEHUPY. 2003. Síntesis de las recomedaciones. In: Derechos Humanos en Paraguay 2003. Asunción: Codehupy, pp. 456-468.

ECHAURI, C. et al. 1992. Hacia una presencia diferente: mujeres, organización y feminismo. Asunción: CDE.

FRANK, J. A.; TAMBORNINO, J. (eds.). 2000. Vocations of political theory. Minneapolis: University of Minnesota.

FREEDEN, M. 2006. Ideology and political theory. Journal of Political 260 Ideologies, v. 11, n. 1, pp. 3-22.

GOLDSTEIN, J. 1988. Ideas, institutions, and american trade policy. International Organization, v. 42, n. 1, pp. 179-217.

GOLDSTEIN, J.; KEOHANE, R. O. 1993. Ideas and foreign policy: an analytical framework. In: GOLDSTEIN, J.; KEOHANE, R. O. (eds.). Ideas and foreign policy: beliefs, institutions and political change. Ithaca: Cornell University, pp. 3-30.

GONZÁLEZ, M. 2015a. Violencia contra la mujer. In: Paraguay a 20 años de Beijing 1995: informe de la sociedad civil sobre el cumplimiento de la Plataforma de Acción de la IV Conferencia Internacional sobre la Mujer. Asunción: CDE; Cladem; CMP; Codehupy; EFC, pp. 71-86. 2015b. Un Estado violento para las mujeres: sin voluntad política ni presupuestos para erradicar la violencia de género. In: Codehupy (2015) Yvypóra Derécho Paraguáipe - Derechos Humanos en Paraguay 2015. Asunción: Codehupy, pp. 403-420.

GOUREVITCH, P. A. 1986. Politics in hard times: comparative responses to international economic crises. Ithaca: Cornell University.

HALL, J. A. Ideas and the social sciences. 1993. In: GOLDSTEIN, J; KEOHANE, R. O. (eds.). Ideas and foreign policy: beliefs, institutions and political change. Ithaca: Cornell University, pp. 31-54. 
HAY, C. 1996. Narrating crisis: the discursive construction of the "Winter of Discontent”. Sociology, v. 30, n. 2, pp. 253-277.

. 2008. Constructivist institutionalism. In: BINDER, S. A.;

RHODES, R. A. W.; ROCKMAN, B. A. (eds.). The Oxford handbook of political institutions. New York: Oxford University, pp. 56-74. Disponível em: <https://goo.gl/AvU9Kk>. Acesso em: 13 nov. 2017.

2011. Ideas and constructions of interests. In: BÉLAND, D.;

COX, R. H. (eds.). Ideas and politics in social sciences research. Oxford:

Oxford University, pp. 65-82.

JACOBS, A. M. 2015. Process-tracing the effects of ideas. In:

BENNETT, A.; CHECKEL, J. T. (eds.). Process tracing in the social sciences: from metaphor to analytic tool. Cambridge: Cambridge University, pp. 41-73.

KINGDON, J. W. 2014. Agendas, alternatives, and public policies. Essex: Pearson.

MAGUIRE, J. M. 1984. Marx y su teoría de la política. México: Fondo de Cultura Económica.

MARTÍNEZ, O. 2001. La violencia contra la mujer. In: Implementación de la Plataforma de Beijing en Paraguay 1995-2000. Asunción: CMP, pp. 71-86.

MARTÍNEZ, O.; SANTAELLA, E. 2002. Derechos de las mujeres: avances

legislativos sin cambios culturales. In: Derechos humanos en Paraguay

2002. Asunción: Codehupy, pp. 143-166.

MARX, K. 2008a. O Dezoito Brumário de Luiz Bonaparte. In:

MARX, K.; ENGELS, F. Obras escolhidas Marx/Engels. Tradução de

Claudia Cavalcanti. São Paulo: Alfa Ômega, v. 1, pp. 189-285. . 2008b. Prefácio à contribuição à crítica da economia política.

In: MARX, K.; ENGELS, F. Obras escolhidas Marx/Engels. Tradução de Claudia Cavalcanti. São Paulo: Alfa Ômega, pp. 300-303. v. 1.

MONTÓRFANO, M. G. 2015. La salud en Paraguay: ¿retrocedió como derecho? De la teoría a la práctica: una brecha que afecta a la población. In: Codehupy (2015) Yvypóra Derécho Paraguáipe-Derechos Humanos en Paraguay 2015. Asunción: Codehupy, pp. 149-164.

NEGRETE, M. 2015. Universalizar los DDHH de las personas que viven con VIH, un nuevo desafio para los próximos años. In: Codehupy (2015) Yuypóra Derécho Paraguáipe: Derechos Humanos en Paraguay 2015. Asunción: Codehupy, pp. 71-84.

PARAGUAY. Ministerio de Salud Pública y Bienestar Social. 1997. Plan Nacional de Salud Reproductiva: versión post-Cairo. Disponível em: <https://goo.gl/58sTwY>. Acesso em: 4 abr. 2017. 
2000. Ley $n^{\circ}$ 1.600, de 4 de julho de 2000. Ley contra la violencia doméstica. Asunción: Cámara de Senadores, 2000. 2003. Plan Nacional de Salud Sexual y Reproductiva, 2003-2008. Disponível em: <https://goo.gl/S1RC4z>. Acesso em: 11 abr. 2017. 2009. Plan Nacional de Salud Sexual y Reproductiva, 2009-2013. Disponível em: <https://goo.gl/qKxqrE>. Acesso em: 15 abr. 2017. 2014. Plan Nacional de Salud Sexual y Reproductiva, 2014-2018. Disponível em: <https://goo.gl/kJbt6U>. Acesso em: 15 abr. 2017. Ley $n^{\circ} 5.777$, de 17 de novembro de 2016. Ley de Protección integral a las mujeres, contra toda forma de violência. Gaceta Oficial de la República del Paraguay, Asunción, n. 252, 29 dez. 2016.

REVOREDO, O. A. 2004. Ideología de género: sus peligros y alcance. In: PONTIFICIO CONSEJO PARA LA FAMILIA. Lexicón: términos ambiguos y discutidos sobre familia, vida y cuestiones éticas. Madrid: Palabra, pp. 593-608.

RIVAROLA, C. R. G. 2002. Manual de la Ley 1600/00 "Contra la violência doméstica”: explicación y aplicación. Asunción: Proyecto Red de Centros de Iniciativas y Desarrollo de la Mujer.

ROTH, G.; SCHLUCHTER, W. 1979. Max Weber's vision of History: ethics and methods. Berkley: University of California.

RUBIN, G.; MACIEL, A. 2005. El Señor es contigo... Feminicidio en Paraguay. Fundación Kuña Aty: Asunción.

SCHAAR, J. H.; WOLIN, S. S. 1963. Essays on the scientific study of politics: a critique. American Political Science Review, v. 57, n. 1, pp. 125-50.

SCHMIDT, V. A. 2010. Taking ideas and discourse seriously: explaining change through discursive institutionalism as the fourth "new institutionalism”. European Political Science Review, v. 2, n. 1, pp. 1-25. 2014. Speaking to the markets or to the people? A discursive institutionalist analysis of the EU's sovereign debt crisis. The British Journal of Politics and International Relations, v. 16, n. 1, pp. 188-209.

SCHMIDT, V. A.; RADAELLI, C. M. 2004. Policy change and discourse in Europe: conceptual and methodological issues. West European Politics, v. 27, n. 2, pp. 183-210.

SCHMIDT, V. A.; THATCHER, M. 2013. Theorizing ideational continuity: the resilience of neo-liberal ideas in Europe. In: SCHMIDT, V. A.; THATCHER, M. (eds.). Resilient liberalism in Europe's political economy. Cambridge: Cambridge University, pp. 1-51.

SOTO, C.; GONZÁLEZ, M.; ELÍAS, M. 2003. Encuesta nacional sobre violencia doméstica e intrafamiliar. Asunción: CDE. 
SZWAKO, J. 2012. Del otro lado de la vereda: luta feminista e construção democrática no Paraguai pós-ditatorial. Tese de doutorado em Ciências Sociais. Campinas: Unicamp.

SZWAKO, J. 2014. O 'mau desempenho' de Lugo: gênero, religião e contramovimento na última destituição presidencial paraguaia. Opinião Pública, v. 20, n. 1, pp. 132-155.

TOCQUEVILLE, A. 2013. O antigo regime e a revolução. Tradução de Rosemary Costhek Abílio. São Paulo: Martins Fontes.

TSEBELIS, G. 1998. Jogos ocultos: escolha racional no campo da politica comparada. Tradução de Luiz Paulo Rouanet. São Paulo: Edusp.

WALBY, S. 2005. Gender mainstreaming: productive tensions in theory and practice. Social Politics, v. 12, n. 3, pp. 321-343.

WEBER, M. 1981. The social psychology of world religions. In:

GERTH, H. H.; MILLS, C. W. (eds.). From Max Weber: essays in sociology. Oxford: Oxford University, pp. 267-301.

WILEY, J. 2006. Sheldon Wolin on theory and the political. Polity, v. 38, n. 2, pp. 211-234.

WOLIN, S. S. 1969. Political theory as a vocation. The American Political Science Review, v. 63, n. 4, pp. 1062-1082. . 1996. The liberal/democratic divide: on Rawls's political liberalism. Political Theory, v. 24, n. 1, pp . 97-119.

WOLIN, S. 2000. Political theory: from vocation to invocation. In: FRANK, J. A.; TAMBORNINO, J. (eds.). Vocations of political theory. Minneapolis: University of Minnesota, pp. 3-22. 


\section{D)}

\section{MOVIMENTOS SOCIAIS COMO TEÓRICOS POLÍTICOS: WOLIN, IDEIAS E POLÍTICAS PÚBLICAS}

RENATO PERISSINOTTO

JOSÉ SZWAKO

Resumo: Este texto sugere que movimentos sociais podem ser entendidos como formuladores de "teoria política", segundo definição específica e crítica, do que seria a vocação teórico-política. Inspirados pela chamada virada ideacional, e aproximando duas discussões afastadas na literatura (a saber, os debates entre teoria política e políticas públicas), este artigo analisa o impacto da ideia de "gênero" em duas políticas estabelecidas no Paraguai. Ao fim, argumentamos que a concepção de teoria política como crítica pública a um viés sistemático considerado injusto é adequada para entender os movimentos sociais não só como portadores de ideias, mas também como "autores em ação" ou "teóricos políticos coletivos".

Palavras-chave: Movimentos Sociais; Paraguai; Virada Ideacional; Teoria Política.

\section{SOCIAL MOVEMENTS AS POLITICAL THEORISTS}

Abstract: This text suggests that social movements can be understood as formulators of 'political theory' according to a specific and critical definition of what the political-theoretical vocation would be. Inspired by the so-called ideational turn, and bringing together two separate discussions in the literature (namely the debates between political theory and public policy), this study analyzes the impact of the idea of 'gender' on two policies in the Paraguayan case. We argue that the conception of political theory as a public criticism to a systematic bias considered unfair is adequate to the understanding 
Resumos | Abstracts

of social movements not only as ideas carriers, but also as 'authors in action' or 'collective political theorists'.

Keywords: Social Movements; Paraguay; Ideational Turn; Political Theory.

Recebido: 08/08/2017 Aprovado: 13/11/2017 